\title{
Lipid and Diabetic Profiles of School Teachers in Afghanistan Facing Food Insecurity and Their Association with Knowledge Relating to Healthy Lifestyle
}

\author{
Ahmad Shekib Arab ${ }^{1}$, Keiko Nakamura ${ }^{*}$, Kaoruko Seino ${ }^{1}$, Shafiqullah Hemat ${ }^{2}$, \\ Mohammad Omar Mashal', Yuri Tashiro' \\ ${ }^{1}$ Department of Global Health Entrepreneurship, Division of Public Health, Tokyo Medical and Dental University, Tokyo, Japan \\ ${ }^{2}$ Ministry of Public Health, Kabul, Afghanistan \\ Email: *nakamura.ith@tmd.ac.jp
}

How to cite this paper: Arab, A.S., Nakamura, K., Seino, K., Hemat, S., Mashal, M.O. and Tashiro, Y. (2019) Lipid and Diabetic Profiles of School Teachers in Afghanistan Facing Food Insecurity and Their Association with Knowledge Relating to Healthy Lifestyle. Food and Nutrition Sciences, 10, 678-693.

https://doi.org/10.4236/fns.2019.106050

Received: May 7, 2019

Accepted: June 24, 2019

Published: June 27, 2019

Copyright $\odot 2019$ by author(s) and Scientific Research Publishing Inc. This work is licensed under the Creative Commons Attribution International License (CC BY 4.0).

http://creativecommons.org/licenses/by/4.0/

\begin{abstract}
Objectives: To investigate lipid and diabetic profiles of school teachers in Kabul, Afghanistan, who face food insecurity, and examine the association of those with the teachers' knowledge of non-communicable diseases (NCDs). Methods: A survey to examine biochemical indicators of NCDs (triglycerides (TG), total cholesterol (TC), high-density lipoprotein (HDL), hemoglobin A1c (HbAlc), blood pressure, height, weight, waist circumference), food insecurity, lifestyle and knowledge of NCDs was conducted among 600 school teachers. Analyses were made of biochemical indicators of NCDs, blood pressure, metabolic syndrome, obesity, and subject's lifestyle in relation to food security and the subject's knowledge of NCDs. Results: Thirty-nine percent of school teachers experienced food insecurity. The percentage of TC $\geq 200 \mathrm{mg} / \mathrm{dL} ; \mathrm{HbAlc} \geq 5.5 \%$; hypertension and metabolic syndrome were $20.2 \%, 29.7 \%, 32.2 \%$ and $33.7 \%$, respectively. Food insecurity was associated with lower fruit and vegetable consumption and higher potato consumption. Food insecurity was associated with increased TC (AOR 2.03; 95\%CI: 1.23 3.34), decreased HDL (AOR 1.70; 95\%CI: 1.12 - 2.58), increased HbAlc (AOR 1.73; 95\%CI: 1.14 - 2.64), hypertension (AOR 1.68; 95\%CI: $1.01-2.80$ ) and diagnosis of metabolic syndrome (AOR 1.78; 95\%CI: 1.18 - 2.68), after adjustment by demographic, socioeconomic and lifestyle variables. Among people living under condition of food insecurity, greater NCD knowledge was associated with smaller prevalence of TG $\geq 150 \mathrm{mg} / \mathrm{dL}, \mathrm{HDL}<40 \mathrm{mg} / \mathrm{dL}$, and diagnosis of metabolic syndrome. Conclusions: Under conditions of food insecurity, diets have less variety and individuals are more likely to exhibit
\end{abstract}


biomedical risk factors of NCDs. Even under conditions of food insecurity, people with knowledge of NCDs may have better coping strategies for their choice of lifestyles and exhibited a lower percentage of risk factors of NCDs.

\section{Keywords}

Food Insecurity, Afghanistan, Non-Communicable Diseases,

Metabolic Syndrome, School Teachers

\section{Introduction}

Food insecurity is defined as the lack of secure access to sufficient amounts of safe and nutritious food for normal growth and development and an active and healthy life [1]. Globally, 124 million people undergoing crises, emergencies, and famines are in need of urgent action against food insecurity [1]. Afghanistan is a country struggling with food insecurity as a consequence of long-term conflicts; its situation is regarded as extremely fragile [2] and expected to be exacerbated [1]. It is reported that 8 million people in Afghanistan (27\% of the population) are very severe or severe food insecure and 5 million (17\% of the population) are moderately food insecure [3]. Compared to 2011-2012 statistics showing 18\% very severe or severe food insecure and $12.2 \%$ moderately food insecure, food insecurity in the country has become worse by 2017 [3]. Food insecurity still needs significant attention in Afghanistan, a country facing conflicts for more than 30 years.

The health impact of food insecurity is not limited to malnutrition of children. Obesity and non-communicable diseases (NCDs) among children and adults are also related to food insecurity [4] [5]. Dietary quality is poor in households under conditions of food insecurity, with reduced consumption of vegetables and fruits and increased consumption of energy-dense foods and carbohydrates [6] [7] [8] [9]. People living under conditions of food insecurity are less physically active [10] and experience more stress [11]. Some studies address associations between food insecurity and chronic diseases such as diabetes, hypertension, and cardiovascular disease, according to self-reported illness history [4]. However, only a limited number of studies reported results of biomedical indicators of NCDs in relation to food insecurity [12]. Therefore, studies analyzing both biomedical indicators of NCDs and of measurements of food insecurity need to be undertaken.

Similar to other low- and middle-income countries, NCDs are leading causes of deaths of adult populations in Afghanistan [13]. The percentage of NCD-related deaths among people under the age of 60 in this country is reported to be the highest in the world [14]. A survey in Kabul City, Afghanistan, with 1172 adult subjects, reported that $57.5 \%$ were overweight or obese; $32.2 \%$ had high blood pressure (BP); 30.0\% showed high total cholesterol (TC) and 41.0\% showed high triglycerides (TG) [15]. There is a growing need of initiatives to prevent and 
control NCDs in Afghanistan.

School teachers can play a major role in health promotion and disease prevention, with their positive and negative behaviors significantly affecting the behaviors of students [16]. Assessment of knowledge and practice of school teachers and measurements of biomedical indicators related to NCDs are regarded as providing baseline information in developing programs for school teachers to take a role of educating school children in health promotion and NCD prevention. However, even those who teach in Kabul, the security conditions are still fragile, so many of them face food insecurity, and its consequences are concerning.

The objectives of this study were to investigate lipid and diabetic profiles of school teachers in Kabul, Afghanistan, who face food insecurity, and examine the association of those with the teachers' knowledge of NCDs.

\section{Methods}

\subsection{Research Setting}

This study was conducted in Kabul City, Afghanistan, in February 2017 in collaboration with the Department of Health Promotion of Ministry of Public Health $(\mathrm{MoPH})$ and the Directorate of Physical Education and School Health of Ministry of Education (MoE), Afghanistan. Kabul City is the capital of Afghanistan and with estimated population of 4.1 million [17]. There were 270 public schools in Kabul City including elementary, secondary and high schools. School teachers are employed by the government. Schools in Kabul City already appointed teachers responsible for health education in individual schools. They are expected to play key roles to advance programs of prevention of diseases. However, teachers themselves did not have systematic training on NCDs.

\subsection{Study Subjects}

School teachers were invited from all public schools by invitation letters from $\mathrm{MoPH}$ and MoE addressed to headmasters of individual schools. Sample size was calculated to be 600 , based on a marginal error of $4 \%$ and $95 \%$ confidence interval. Those who consented to participate in the study, voluntarily, were enrolled in the study until the number of participants reached 600 . They were from a total of 210 schools, representing $77.8 \%$ of total number of public schools in Kabul City.

\subsection{Questionnaire Interview and Health Examination}

The study participants attended a face-to-face interview in a predefined venue with facilities for physical examination, blood sample collection and testing. Each interview took 20 - 30 minutes, followed by physical health examination and blood sample collection for biochemical examination. Interviewers participated in 2-days training for interviews. Questionnaire included demographic and socioeconomic characteristics of the subjects, food insecurity, lifestyles, and 
knowledge about NCDs. Physical examination included measurements of weight, height, waist circumference (WC), systolic blood pressure (SBP), and diastolic blood pressure (DBP), by trained health workers. Ten $\mathrm{ml}$ intravenous blood samples were collected to measure TG, TC, high-density lipoprotein (HDL) cholesterol, low-density lipoprotein (LDL) cholesterol, and hemoglobin Alc (HbAlc). The lipid profile measured using a kit method on semi-automated clinical chemistry analyzer (Micro-lab 300), and HbAlc measured by fully automated Boronate affinity chromatography (Clover A1c) with measure time of 5 minute and test range of $4 \%-14 \%$.

\subsection{Study Variables}

\subsubsection{Demographic and Socioeconomic Variables}

The questions related to demographic and socioeconomic characteristics included participants' gender, age, marital status, level of education, household income and number of household members. Teaching subjects at school of participants were also noted. The following categories were applied to individual variables: age, $\leq 30$ or $\geq 31$ years old; marital status, currently married or other; level of education, graduate of high school (12 years of education) or 2-year college (14 years of education) or college or university or higher degree schools; household monthly income, $\leq 10,000$ Afghani (Afs) ( $\leq 150$ USD) or 10,001 20,000 Afs (150 - 300 USD) or $>20,001 \mathrm{Afs}$ ( $>300$ USD), 1 Afs was equivalent to 0.0150 USD as of January 2017); number of household members, $\leq 4$ or $5-8$ or 9 - 12 or $\geq 13$; and teaching subjects, science/social science/language/others.

\subsubsection{Food Insecurity Variables}

According to a measurement of food security developed by the Center for Disease Control, USA [18], household food insecurity was evaluated for 5 food groups by a question on worry for rice in the past 12 months. Worry for food was also asked for five food groups: rice, bread, vegetable, fruit, and meat with three different levels. A composite score, a sum of scores given to 5 items was created, the minimum and maximum values were 5 and 15 . Cronbach's alpha score was 0.826 . Finally, a single score was developed as a proxy measure. Those answered "sometimes" or "always" worried about rice in the past 12 months were categorized as "food insecure" and "not at all" worried about rice in the past 12 months were categorized as "food secure".

\subsubsection{Lifestyle Variables}

Questionnaires on lifestyle behaviors included questions related to the consumptions of different foods (fruits; raw vegetables; cooked vegetables; red meat or chicken; processed, fried, or fast food; potatoes; soft drinks; beans; sweets; nuts) over the past 7 days, eating behaviors (eating breakfast every day, eating outside of home) and a question related to daily physical activities (walk or exercise). Answers to food frequencies were taken by 5 responses (never/less often/1 - 3 days per week/4 - 6 days per week/every day). According to the distribution of consumption of fruits, vegetables, beans and potatoes per week were catego- 
rized as consumption $\geq 4$ days/week or $<4$ days/week. Responses to other items were categorized as $\geq 1$ day/week or $<1$ day/week. Answers to the questions for eating behaviors were categorized yes vs. no. Level of physical activity was categorized $\geq 1$ hour/day or $<1$ hour/day.

\subsubsection{Knowledge on NCDs Variables}

Questions related to knowledge about NCDs included five questions: general perception about NCDs, modifiable risk factors, indicator of BMI, physical activity and second-hand smoke. A correct answer to each item was given a score of 1 and incorrect response was given a score of zero and then a total composite score was generated. The final scores were divided into two groups: high knowledge group with score of 4 or 5 and low knowledge group with other scores.

\subsubsection{Biomedical and Physical Indicators}

According to the results of physical examination and blood examination, the following categories were applied for biomedical and physical indicators. TG, $\geq 150 \mathrm{mg} / \mathrm{dL}$ or $<150 \mathrm{mg} / \mathrm{dL}$; TC, $\geq 200 \mathrm{mg} / \mathrm{dL}$ or $<200 \mathrm{mg} / \mathrm{dL} ; \mathrm{HDL},<40 \mathrm{mg} / \mathrm{dL}$ or $\geq 40 \mathrm{mg} / \mathrm{dL}$; HbAlc, $\geq 5.5 \%$ or $<5.5 \%$. Cut off point for HbAlc was decided according to a review of $\mathrm{HbA1c}$ and risk of diabetes and a study of sensitivity and specificity analysis of HbAlc and diagnosis of type 2 diabetes [19] [20]. "Hypertension" was defined as systolic/diastolic blood pressure $\geq 130 / 85 \mathrm{mmHg}$. "Central obesity" was defined as WC $\geq 80 \mathrm{~cm}$ for women and $\geq 94 \mathrm{~cm}$ for men. "Obesity" was defined as body mass index (BMI) $\geq 30$. "Metabolic syndrome" was defined as satisfying three or more criteria of the followings: TG $\geq 150$ $\mathrm{mg} / \mathrm{dL}, \mathrm{HDL}<40 \mathrm{mg} / \mathrm{dL}, \mathrm{HbA} 1 \mathrm{c}>5.5 \%$, "hypertension", and "central obesity" [21].

\subsection{Analysis}

The chi-square test was used to compare household food insecurity status by demographic and socioeconomic characteristics, lifestyles and knowledge on NCDs. Multivariate logistic regression analysis was performed to investigate the associations between household food insecurity and biomedical and physical indicators, including increased TG, increased TC, decreased HDL, increased HbA1c, hypertension, central obesity, obesity and metabolic syndrome, adjusting for age, gender, household income, education, vegetable consumption, physical activity, NCD knowledge and teaching subjects. The results of the logistic regression analysis were presented with adjusted odds ratio (AOR), with 95\% confidence interval (CI). Finally, independent associations between NCD knowledge and biomedical and physical indicators were examined in food insecure and secure group, separately, by multivariate logistic regression analysis. Data were analyzed using IBM SPSS version 23 for Windows (IBM, Armonk, NY). In all analyses, $P<0.05$ was taken to indicate statistical significance.

\subsection{Ethics}

The study protocol was approved by the Institutional Review Board (IRB) of 
Tokyo Medical and Dental University (M2016-212). Informed consent was obtained from all participants; this research was conducted in accordance with the tenets of Declaration of Helsinki.

\section{Results}

\subsection{Food Insecurity and Demographic and Sociodemographic Characteristics}

Among 600 school teachers, 234 (39.0\%) were facing food insecurity. Mean and SD of food insecurity composite score for "food insecure" and "food secure" groups were $10.2 \pm 2.2$ and $6.5 \pm 1.8$. The participants ranged in age from 18 to 66 years old and $69.3 \%$ of the subjects were females. Those who were aged 31 and above were $76.3 \%$, and $79.7 \%$ were married. Subjects completed college/university or higher education were $35.5 \%$, and subjects from household monthly income 10,000 Afghani (150 USD) or less were 31.7\%. Subjects with household members between 5 and 8 were $56.5 \%$. Subjects who were teaching science at school were $35.5 \%$, those teaching languages were $28.7 \%$.

Table 1 shows prevalence of food insecurity by demographic and socioeconomic characteristics of the subjects. Teachers 31 years and older and currently married were more likely to be food insecure ( $P=0.03, P<0.01$, respectively). In relation to family size, although statistical significant difference in food security status by number of household members was not present, teachers from households with 13 or more number showed higher proportion of food insecurity. Prevalence of food insecurity was significantly different by household income level $(P=0.03)$.

\subsection{Food Insecurity and Lifestyle Practices and Knowledge Related NCDs}

Table 2 shows lifestyle behaviors and knowledge on NCDs of the study subjects in food insecure and secure conditions, separately. Food insecurity was significantly associated with less frequent consumption of fruits $(P<0.01)$, raw and cooked vegetables $(P<0.01$, respectively), red meat or chicken $(P=0.02)$, and nuts $(P<0.01)$, but significantly associated with more frequent consumption of potatoes $(P<0.01)$. Food insecurity was significantly associated with not eating breakfast every day $(P<0.01)$, and not eating outside of home $(P<0.01)$. There were no statistical differences observed in distribution of NCD knowledge score in food insecure and secure groups.

\subsection{Results of Physical and Biomedical Examination}

Overall prevalence of obesity (BMI $\geq 30$ ) was $18.3 \%$ and overweight or obesity (BMI $\geq 25$ ) was $58.3 \%$. The prevalence of hypertension was $32.2 \%$. The percentage of participants with TG $\geq 150 \mathrm{mg} / \mathrm{dL}, \mathrm{TC} \geq 200 \mathrm{mg} / \mathrm{dL}, \mathrm{HDL}<40 \mathrm{mg} / \mathrm{dL}$ were $43.5 \%, 20.2 \%$ and $28.8 \%$, respectively. The percentage of participants with $\mathrm{HbAlc} \geq 5.5 \%$ or $\mathrm{HbAlc} \geq 6.5 \%$ were $29.7 \%$ and $7.0 \%$, respectively. The 
Table 1. Prevalence of household food insecurity by demographic and socioeconomic characteristics of the study subjects, school teachers in Afghanistan $(n=600)$.

\begin{tabular}{|c|c|c|c|c|}
\hline & \multirow{2}{*}{$\mathrm{n}$} & \multicolumn{2}{|c|}{ Household food security } & \multirow{2}{*}{$P$-value } \\
\hline & & Insecure (\%) & Secure (\%) & \\
\hline \multicolumn{5}{|l|}{ Gender } \\
\hline Male & 184 & 42.4 & 57.6 & 0.26 \\
\hline Female & 416 & 37.5 & 62.5 & \\
\hline \multicolumn{5}{|l|}{ Age (years) } \\
\hline$\leq 30$ & 142 & 31.0 & 69.0 & 0.03 \\
\hline$\geq 31$ & 458 & 41.5 & 58.5 & \\
\hline \multicolumn{5}{|l|}{ Marital status } \\
\hline Currently married & 478 & 42.5 & 57.5 & $<0.01$ \\
\hline Other & 121 & 24.8 & 75.2 & \\
\hline \multicolumn{5}{|l|}{ Level of education } \\
\hline Graduate of high school & 25 & 40.0 & 60.0 & 0.37 \\
\hline Graduate of 2-year college & 362 & 41.2 & 58.8 & \\
\hline Graduate of college/university or higher & 213 & 35.2 & 64.8 & \\
\hline \multicolumn{5}{|l|}{ Household monthly income (Afghani) ${ }^{\mathrm{a}}$} \\
\hline$\leq 10,000$ & 190 & 43.2 & 56.8 & 0.03 \\
\hline $10,001-20,000$ & 272 & 40.8 & 59.2 & \\
\hline$>20,000$ & 138 & 29.7 & 70.3 & \\
\hline \multicolumn{5}{|l|}{ Number of household members } \\
\hline$\leq 4$ & 109 & 39.4 & 60.6 & 0.95 \\
\hline $5-8$ & 339 & 38.6 & 61.4 & \\
\hline $9-12$ & 115 & 38.3 & 61.7 & \\
\hline$\geq 13$ & 37 & 43.2 & 56.8 & \\
\hline \multicolumn{5}{|l|}{ Teaching subjects } \\
\hline Science & 213 & 39.0 & 61.0 & 0.76 \\
\hline Social science & 59 & 33.9 & 66.1 & \\
\hline Language & 172 & 38.4 & 61.6 & \\
\hline Others & 156 & 41.7 & 58.3 & \\
\hline
\end{tabular}

${ }^{\mathrm{a}}$ Afghani $=0.015$ USD, as of January 2017.

Table 2. Lifestyle behaviors and knowledge on NCDs of the study subjects by household food insecurity, school teachers in Afghanistan $(n=600)$.

\begin{tabular}{ccccc}
\hline & & \multicolumn{2}{c}{ Household food security } & \\
& $\mathrm{n}$ & Insecure & Secure & $P$-value \\
& & & & \\
& & & & \\
Food consumption per week & & & & \\
Fruits & 366 & 77.4 & 50.5 & $<0.01$ \\
$<4$ days & 234 & 22.6 & 49.5 & \\
\hline 4 days & & & & \\
\hline
\end{tabular}




\section{Continued}

Raw vegetables

$$
<4 \text { days }
$$$$
\geq 4 \text { days }
$$

337

Cooked vegetables

$$
<4 \text { days }
$$$$
\geq 4 \text { days }
$$

198

Red meat or chicken

$<1$ day
$\geq 1$ days

Processed, fried, or fast food

$$
\begin{aligned}
& <1 \text { day } \\
& \geq 1 \text { days }
\end{aligned}
$$

\section{Potatoes}

$$
\begin{aligned}
& <4 \text { days } \\
& \geq 4 \text { days }
\end{aligned}
$$

Soft drinks

$$
\begin{aligned}
& <1 \text { day } \\
& \geq 1 \text { days } \\
& \text { Beans } \\
& <4 \text { days }
\end{aligned}
$$

$\geq 4$ days

\section{Sweets}

$<1$ day

$\geq 1$ day

Nuts

$<1$ day

$\geq 1$ day

Eating behaviors

Daily breakfast

Yes
No

Eating outside

Yes

No

Physical activity and exercise

Walk or exercise per day

$$
\begin{aligned}
& <1 \text { hour } \\
& \geq 1 \text { hour }
\end{aligned}
$$

Knowledge about NCDs

NCD knowledge score

\begin{tabular}{lllll}
$<4$ & 479 & 78.6 & 80.8 & 0.53 \\
$\geq 4$ & 120 & 21.4 & 19.2 & \\
\hline
\end{tabular}


percentage of participants diagnosed as metabolic syndrome among participants was $33.7 \%$.

\subsection{Food Insecurity and Biomedical and Physical Indicators Related NCDs}

Table 3 shows associations between biomedical and physical indicators, and food insecurity after adjustment of age, gender, household income, education, vegetable consumption, physical activity, NCD knowledge and teaching subjects. The percentage of subjects with elevated TC was $21.5 \%$ in the food insecure group and $11.9 \%$ in the food secure group. Higher TC was significantly associated with food insecurity, after adjustment of other variables (AOR 2.03; 95\%CI: 1.23 - 3.34). The percentage of subjects with decreased HDL was $30.8 \%$ in the food insecure group and $21.1 \%$ in the food secure group. Lower HDL was significantly associated with food insecurity, after adjustment of other variables (AOR 1.70; 95\%CI: 1.12 - 2.58). The percentage of subjects with increased HbAlc was $29.7 \%$ in the food insecure group and $20.6 \%$ in the food secure group. Higher HbA1c was significantly associated with food insecurity, after adjustment of other variables (AOR 1.73; 95\%CI: 1.14 - 2.64). The percentage of subjects diagnosed as hypertension was $22.1 \%$ in the food insecure group and $14.6 \%$ in the food secure group. Diagnosis of hypertension was significantly associated with food insecurity, after adjustment of other variables (AOR 1.68; 95\%CI: 1.01 - 2.80). The percentage of subjects diagnosed as metabolic syndrome was $36.0 \%$ in the food insecure group and $24.2 \%$ in the food secure group. Diagnosis of metabolic syndrome was significantly associated with food insecurity, after adjustment of other variables (AOR 1.78; 95\%CI: 1.18 - 2.68).

Table 3. Associations of biomedical and physical indicators related to NCDs and food insecurity, independent of demographic, socioeconomic characteristics, lifestyles and NCD knowledge.

\begin{tabular}{|c|c|c|c|c|c|c|}
\hline \multirow{3}{*}{$\begin{array}{l}\text { Biomedical and physical indicators } \\
\qquad \mathrm{TG} \geq 150 \mathrm{mg} / \mathrm{dL}\end{array}$} & \multirow{3}{*}{$\begin{array}{c}\mathrm{n}^{*} \\
572^{\mathrm{a})}\end{array}$} & \multicolumn{2}{|c|}{ Prevalence } & & & \multirow[b]{2}{*}{$P$-value } \\
\hline & & $\begin{array}{l}\text { Among food } \\
\text { insecure group (\%) }\end{array}$ & $\begin{array}{c}\text { Among food } \\
\text { secure group (\%) }\end{array}$ & \multicolumn{2}{|c|}{$\operatorname{AOR}(95 \% \mathrm{CI})$} & \\
\hline & & 46.0 & 37.5 & 1.31 & $(0.92-1.87)$ & 0.14 \\
\hline $\mathrm{TC} \geq 200 \mathrm{mg} / \mathrm{dL}$ & $549^{\mathrm{b})}$ & 21.5 & 11.9 & 2.03 & $(1.23-3.34)$ & $<0.01$ \\
\hline $\mathrm{HDL}<40 \mathrm{mg} / \mathrm{dL}$ & $549^{\mathrm{b})}$ & 30.8 & 21.1 & 1.70 & $(1.12-2.58)$ & 0.01 \\
\hline HbAlc $\geq 5.5 \%$ & $550^{c)}$ & 29.7 & 20.6 & 1.73 & $(1.14-2.64)$ & 0.01 \\
\hline $\mathrm{BP} \geq 130 / 85$ (hypertension) & $491^{\mathrm{d})}$ & 22.1 & 14.6 & 1.68 & $(1.01-2.80)$ & 0.04 \\
\hline $\begin{array}{c}\text { WC } \geq 94 \mathrm{~cm} \text { for men; } \\
80 \mathrm{~cm} \text { for women (central obesity) }\end{array}$ & 599 & 69.2 & 67.2 & 1.24 & $(0.80-1.92)$ & 0.34 \\
\hline BMI $\geq 30$ (obesity) & 599 & 20.9 & 16.7 & 1.32 & $(0.83-2.07)$ & 0.24 \\
\hline Metabolic syndrome & $537^{\mathrm{e})}$ & 36.0 & 24.2 & 1.78 & $(1.18-2.68)$ & $<0.01$ \\
\hline
\end{tabular}

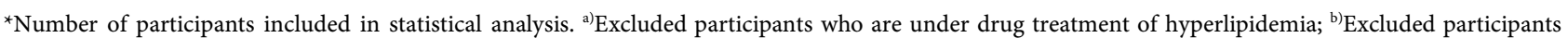
who are under drug treatment of hyperlipidemia or have cholesterol $\geq 240$; ${ }^{c}$ Excluded participants who are under drug treatment of diabetes or HbAlc $\geq$ 6.5 ; ${ }^{\text {d) }}$ Excluded participants who are under drug treatment of hypertension or BP $\geq 140 / 90$; ${ }^{\text {e) }}$ Excluded participants who are under drug treatment of hyperlipidemia, diabetes or hypertension. AOR: adjusted odds ratio, adjusted by age, gender, household income, education, vegetable consumption, physical activity, NCD knowledge and teaching subject. $\mathrm{TG}=$ triglycerides; $\mathrm{TC}=$ total cholesterol; $\mathrm{HDL}=$ high-density lipoprotein; $\mathrm{BP}=\mathrm{blood}$ pressure; $\mathrm{WC}=$ waist circumference; $\mathrm{CI}=$ confidence interval. 


\subsection{NCD Related Knowledge and Biomedical Indicators among Food Insecure and Secure Groups}

Table 4 presents associations between biomedical and physical indicators, and NCD related knowledge in food insecure and secure groups. Among people living under condition of food insecurity, greater NCD knowledge was associated with smaller prevalence of TG $\geq 150 \mathrm{mg} / \mathrm{dL}, \mathrm{HDL}<40 \mathrm{mg} / \mathrm{dL}$, and diagnosis of metabolic syndrome ( $P=0.01, P=0.03, P=0.02$, respectively), after adjustment of demographic, socioeconomic and lifestyle variables. However, under food secure condition, none of the associations between NCD knowledge and biomedical or physical indicators were observed.

Table 4. Associations of biomedical and physical indicators related to NCDs and knowledge on NCDs, independent of demographic, socioeconomic characteristics and lifestyles, in food insecure and secure groups.

\begin{tabular}{|c|c|c|c|c|c|c|}
\hline \multirow[b]{2}{*}{ Biomedical and physical indicators } & \multirow[b]{2}{*}{$\mathrm{n}^{*}$} & \multicolumn{2}{|c|}{ Prevalence } & \multirow{2}{*}{\multicolumn{2}{|c|}{$\operatorname{AOR}(95 \% \mathrm{CI})$}} & \multirow[b]{2}{*}{$P$-value } \\
\hline & & $\begin{array}{l}\text { Among high knowledge } \\
(\%)\end{array}$ & $\begin{array}{c}\text { Among low knowledge } \\
(\%)\end{array}$ & & & \\
\hline \multicolumn{7}{|l|}{ Food insecure } \\
\hline $\mathrm{TG} \geq 150 \mathrm{mg} / \mathrm{dL}$ & $226^{a)}$ & 31.9 & 49.7 & 0.41 & $(0.20-0.84)$ & 0.01 \\
\hline $\mathrm{TC} \geq 200 \mathrm{mg} / \mathrm{dL}$ & $214^{\mathrm{b})}$ & 12.8 & 24.0 & 0.46 & $(0.17-1.20)$ & 0.11 \\
\hline $\mathrm{HDL}<40 \mathrm{mg} / \mathrm{dL}$ & $214^{\mathrm{b})}$ & 19.1 & 34.1 & 0.40 & $(0.17-0.91)$ & 0.03 \\
\hline $\mathrm{HbA} 1 \mathrm{c} \geq 5.5 \%$ & $212^{c)}$ & 22.7 & 31.5 & 0.62 & $(0.27-1.42)$ & 0.26 \\
\hline $\mathrm{BP} \geq 130 / 85$ (hypertension) & $190^{\mathrm{d})}$ & 17.1 & 23.5 & 0.72 & $(0.26-1.97)$ & 0.52 \\
\hline $\begin{array}{l}\mathrm{WC} \geq 94 \mathrm{~cm} \text { for men; } 80 \mathrm{~cm} \\
\text { for women (central obesity) }\end{array}$ & 234 & 64.0 & 70.7 & 0.82 & $(0.36-1.88)$ & 0.64 \\
\hline BMI $\geq 30$ (obesity) & 234 & 24.0 & 20.1 & 1.81 & $(0.74-4.42)$ & 0.19 \\
\hline Metabolic syndrome & $211^{\mathrm{e})}$ & 22.2 & 39.8 & 0.38 & $(0.16-0.87)$ & 0.02 \\
\hline \multicolumn{7}{|l|}{ Food secure } \\
\hline $\mathrm{TG} \geq 150 \mathrm{mg} / \mathrm{dL}$ & $346^{\mathrm{a})}$ & 38.8 & 37.3 & 1.10 & $(0.63-1.95)$ & 0.73 \\
\hline $\mathrm{TC} \geq 200 \mathrm{mg} / \mathrm{dL}$ & $335^{\mathrm{b})}$ & 7.9 & 12.9 & 0.49 & $(0.18-1.35)$ & 0.17 \\
\hline $\mathrm{HDL}<40 \mathrm{mg} / \mathrm{dL}$ & $335^{b)}$ & 15.9 & 22.4 & 0.57 & $(0.27-1.21)$ & 0.14 \\
\hline $\mathrm{HbA} 1 \mathrm{c} \geq 5.5 \%$ & $338^{c)}$ & 25.0 & 19.3 & 1.31 & $(0.67-2.55)$ & 0.44 \\
\hline $\mathrm{BP} \geq 130 / 85$ (hypertension) & $301^{\mathrm{d})}$ & 22.0 & 12.4 & 2.04 & $(0.94-4.45)$ & 0.07 \\
\hline $\begin{array}{l}\mathrm{WC} \geq 94 \mathrm{~cm} \text { for men; } 80 \mathrm{~cm} \\
\text { for women (central obesity) }\end{array}$ & 365 & 70.0 & 66.8 & 0.91 & $(0.46-1.82)$ & 0.79 \\
\hline BMI $\geq 30$ (obesity) & 365 & 17.1 & 16.6 & 0.97 & $(0.47-2.01)$ & 0.94 \\
\hline Metabolic syndrome & $326^{\mathrm{e})}$ & 30.6 & 22.7 & 1.38 & $(0.72-2.63)$ & 0.33 \\
\hline
\end{tabular}

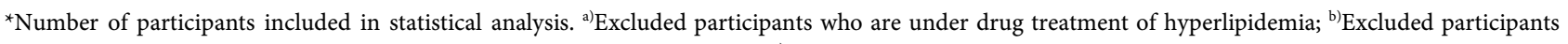
who are under drug treatment of hyperlipidemia or have cholesterol $\geq 240$; ${ }^{\circ}$ Excluded participants who are under drug treatment of diabetes or HbAlc $\geq$ 6.5 ; ${ }^{\mathrm{d})}$ Excluded participants who are under drug treatment of hypertension or BP $\geq 140 / 90$; ${ }^{\mathrm{e}}$ Excluded participants who are under drug treatment of hyperlipidemia, diabetes or hypertension; AOR: adjusted odds ratio, adjusted by age, gender, household income, education, vegetable consumption, physical activity, and teaching subject. $\mathrm{TG}=$ triglycerides; $\mathrm{TC}=$ total cholesterol; $\mathrm{HDL}=$ high-density lipoprotein; $\mathrm{BP}=$ blood pressure; $\mathrm{WC}=$ waist circumference; $\mathrm{CI}=$ confidence interval. 


\section{Discussion}

The results of the present study indicated that more than one-third of school teachers in Kabul City lived under food insecurity and exhibited biomedical indicators showing higher risk of NCDs. The food insecurity among school teachers was more prevalent among those with higher age, married, and those with lower household income. Food insecurity was significantly associated with less consumption of fruits and vegetables. Food insecurity was significantly associated with increased TC, decreased HDL, increased $\mathrm{HbAlc}$, hypertension and metabolic syndrome. The results of our analysis also indicated that even among those who lived under food insecurity, significantly healthier lipid profiles and fewer diagnosis of metabolic syndrome were observed when their level of knowledge on NCD was high.

\subsection{Food Insecurity}

School teachers were not exception from facing food insecurity in Kabul City, Afghanistan. This study showed $39.0 \%$ of teachers faced with food insecurity, which is similar prevalence among general population. Although most of the teachers completed education at least 14 years, their daily life was threatened by inconsistent access to food. Afghanistan Living Condition Survey reported prevalence of food insecurity among school teachers as $45.3 \%$, a little higher than the average of all occupational groups [3]. When health promotion program for children will be developed and school teachers will be asked to take roles in health education, school teachers who face with food insecurity themselves should be well considered.

\subsection{Lifestyle under Food Insecurity}

Reports from Vietnam, Lebanon, Portugal, and the US including people under fragile condition showed that individuals experiencing food insecurity have a diet with reduced variety, and consume fewer foods rich in fiber, antioxidants, and micronutrients including fruits and vegetables [7] [22] [23] [24]. Our study from Kabul, Afghanistan, also exhibited similar dietary pattern under food insecurity. A study performed in the US indicated a significant association between food insecurity and lower levels of physical activity [10]. Although statistically not significant, our study demonstrated that physical activity of participants from a food insecure condition is less frequent than those from a food-secure environment. In addition to the dietary and physical activity patterns under food insecurity, psychological stress affecting cardiovascular system [25], are also concerning under food insecurity.

\subsection{Increased Risk of NCDs under Food Insecurity}

The results of biochemical and physical examination of 600 participants showed a high proportion of overweight, obesity and NCDs. The previous study conducted in Kabul also found similar proportion of overweight and obesity, and 
NCDs [15]. The finding of current study confirmed that food insecurity is an independent factor associated with unfavorable lipid and diabetic profiles, hypertension and metabolic syndrome. This result is particularly important because this is from an area facing a long-term conflict, where one third of the population are facing food insecurity. Most of the reports on food insecurity and NCD risk factors are conducted in high-income countries [12] [26] [27] [28] [29], or based on self-reported illness conditions [30] [31] [32], or showing mixed results [33] [34]. It should be noted that number of biomedical and physical indicators of NCDs are independently associated with food insecurity in Afghanistan.

\subsection{Potential Influence of Knowledge Related to NCDs to Reduce Risk}

Knowledge plays an important role in lifestyle-related diseases. The participants in the present study from the food insecurity group with good knowledge of NCD showed healthier lipid profiles and less metabolic syndrome. However, among those living under food secure condition, these associations were not observed. These observations indicated that even when people are left under food insecure condition, if they have appropriate knowledge about NCDs, they could manage to keep a little better health condition with lower probability of NCDs. As a coping strategy, people from food insecure households relay on energy dense foods which are rich in carbohydrate and fat and reduce the consumption of expensive foods such as fruits [22]. People with a better knowledge about NCD, even under condition of food insecurity, may tend to select a healthier coping strategy as limiting consumption of carbohydrates, fats and salt, and increasing consumption of vegetables and selecting to be more active.

These results encourage to develop educational program to improve people's knowledge on NCDs. A diabetes educational intervention to patients experiencing food insecurity suggested significant improvement in diabetic control and efficacy [35]. In Afghanistan, where a large number of people are still facing food insecurity, health education program to improve knowledge on NCDs prevention and control should be urgently developed.

\subsection{Strength and Limitations}

In contrast to other studies that relied on self-reported health status and illness history, the outcomes were measured objectively in the present study. We used $\mathrm{HbA1c}$ value as this test does not require fasting, and assesses the glycemic trends over the previous several months. Having the study sample from a specific group, teachers working at public schools, resulted in a reduction in variation in level of education and income among participants. This facilitated development of a simplified model to examine associations between food insecurity and health indicators.

As this was a cross-sectional study, we carefully discussed the associations of variables and not specifying causal relationships. The study was conducted in 
winter. Percentage of food insecurity is reported to be high in winter season [3], therefore absolute prevalence of food insecurity should be interpreted carefully. Regarding the generalizability, the sample size was large and participants were from all 22 municipality districts of Kabul City, which has the largest population in Afghanistan and is comprised of people from different provinces and ethnicity groups, however, caution is advised when generalizing the findings to the overall population.

\section{Conclusion}

Among teachers working in public schools in Kabul, Afghanistan, 39\% reported that they were living under conditions of food insecurity. People under food insecurity had a smaller variety of foods in their diet, and they skipped breakfast at a higher rate than those living under food secure conditions. Afghan teachers under food insecurity were more likely to exhibit adverse lipid and diabetic profiles and to be diagnosed with hypertension or metabolic syndrome. Teachers living under food insecurity, but with good knowledge relating to NCDs, exhibited healthier lipid profiles and fewer metabolic syndrome. In Afghanistan, where many people are still facing food insecurity, health education programs to improve knowledge on NCDs are needed, in addition to the continuous efforts to ensure food security to the population.

\section{Acknowledgements}

The authors acknowledge Department of Health Promotion of MoPH, Afghanistan, and Physical Education and School Health Directorate of MoE, Afghanistan. Particular support to implement the study was given by Dr. Bashir Noormal, Director of Afghan National Public Health Institute, MoPH; Mr. Mohammad Akbar Omarkhil, Director of Physical Education and School Health Directorate, MoE; and Dr. Sayed Maqbool Hashemi, Head of Health Education Section, MoE. The authors also appreciate the survey team, school principals, and school teachers who participated in the survey. This study was funded by Japan Society for Promotion Science (JSPS), Grant numbers 26305022 and $17 \mathrm{H} 02164$.

\section{Conflicts of Interest}

The authors declare no conflicts of interest regarding the publication of this paper.

\section{References}

[1] Food Security Information Network (FNIS) (2018) Global Report on Food Crises 2018. World Food Program, Rome. https://www.wfp.org/content/global-report-food-crises-2018

[2] Food and Agriculture Organization (FAO) International Fund for Agricultural Development, United Nations Children's Fund, Wrould Food Program, World Health 
Orgaanization (2017) The State of Food Security and Nutrition in the World 2017. FAO, Rome.

[3] Centeral Statistics Organization (CSO) of the Government of the Islamic Republic of Afghanistan (2018) Afghanistan Living Conditions Survey 2016-17. CSO, Kabul.

[4] Weaver, L.J. and Fasel, C.B. (2018) A Systematic Review of the Literature on the Relationships between Chronic Diseases and Food Insecurity. Food and Nutrition Science, 9, 519-541. https://doi.org/10.4236/fns.2018.95040

[5] Tanumihardjo, S.A., Anderson, C., Kaufer-Horwitz, M., et al. (2007) Poverty, Obesity, and Malnutrition: An International Perspective Recognizing the Paradox. Journal of American Dietetic Association, 107, 1966-1972.

https://doi.org/10.1016/j.jada.2007.08.007

[6] Belachew, T., Lindstrom, D., Gebremariam, A., et al. (2013) Food Insecurity, Food Based Coping Strategies and Suboptimal Dietary Practices of Adolescents in Jimma Zone Southwest Ethiopia. PLoS ONE, 8, e57643. https://doi.org/10.1371/journal.pone.0057643

[7] Hanson, K.L. and Connor, L.M. (2014) Food Insecurity and Dietary Quality in US Adults and Children: A Systematic Review. American Journal of Clinical Nutrition, 100, 684-692. https://doi.org/10.3945/ajcn.114.084525

[8] Simmet, A., Depa, J., Tinnemann, P. and Stroebele-Benschop, N. (2017) The Dietary Quality of Food Pantry Users: A Systematic Review of Existing Literature. Journal of the Academy of Nutrition and Dietetics, 117, 563-576. https://doi.org/10.1016/j.jand.2016.08.014

[9] Johnson, C.M., Sharkey, J.R., Lackey, M.J., et al. (2018) Relationship of Food Insecurity to Women's Dietary Outcomes: A Systematic Review. Nutrition Reviews, 76, 910-928. https://doi.org/10.1093/nutrit/nuy042

[10] To, Q.G., Frongillo, E.A., Gallegos, D. and Moore, J.B. (2014) Household Food Insecurity Is Associated with Less Physical Activity among Children and Adults in the U.S. Population. The Journal of Nutrition, 144, 1797-1802. https://doi.org/10.3945/jn.114.198184

[11] Jones, A.D. (2017) Food Insecurity and Mental Health Status: A Global Analysis of 149 Countries. American Journal of Preventive Medicine, 53, 264-273. https://doi.org/10.1016/j.amepre.2017.04.008

[12] Shin, J.I., Bautista, L.E., Walsh, M.C., Malecki, K.C. and Nieto, F.J. (2015) Food Insecurity and Dyslipidemia in a Representative Population-Based Sample in the US. Preventive Medicine, 77, 186-190. https://doi.org/10.1016/j.ypmed.2015.05.009

[13] Ministry of Public Health (2010) Afghanistan Mortality Survey 2010. Ministry of Public Health, Kabul, 1-285.

[14] Zarocostas, J. (2011) Deaths from Non-Communicable Diseases Are Highest in Afghanistan, Lowest in Sweden. BMJ, 343, d5876. https://doi.org/10.1136/bmj.d5876

[15] Saeed, K.M.I. (2017) Burden of Hypertension in the Capital of Afghanistan: A Cross-Sectional Study in Kabul City, 2015. Intenational Journal of Hypertenssion, 2017, Article ID: 3483872. https://doi.org/10.1155/2017/3483872

[16] He, L., Zhai, Y., Engelgau, M., et al. (2014) Association of Children's Eating Behaviors with Parental Education, and Teachers' Health Awareness, Attitudes and Behaviors: A National School-Based Survey in China. European Journal of Public Health, 24, 880-887. https://doi.org/10.1093/eurpub/ckt177

[17] Centeral Statistics Organization (CSO) of the Government of the Islamic Republic 
of Afghanistan (2018) Esstimated Population of Afghanistan 2018-19. CSO, Kabul.

[18] Pan, L., Sherry, B., Njai, R. and Blanck, H.M. (2012) Food Insecurity Is Associated with Obesity among US Adults in 12 States. Journal of Academic Nutrition and Diet, 112, 1403-1409. https://doi.org/10.1016/j.jand.2012.06.011

[19] Zhang, X., Gregg, E.W., Williamson, D.F., et al. (2010) A1C Level and Future Risk of Diabetes: A Systematic Review. Diabetes Care, 33, 1665-1673. https://doi.org/10.1016/j.jand.2012.06.011

[20] Razi, F., Khashayar, P., Ghodssi-Ghassemabadi, R., et al. (2018) Optimal Glycated Hemoglobin Cutoff Point for Diagnosis of Type 2 Diabetes in Iranian Adults. Canadian Journal of Diabetes, 42, 582-587. https://doi.org/10.1016/j.jcjd.2018.03.005

[21] Alberti, K.G.M.M., Eckel, R.H., Grundy, S.M., et al. (2009) Harmonizing the Metabolic Syndrome. Circulation, 120, 1640-1645. https://doi.org/10.1161/CIRCULATIONAHA.109.192644

[22] Vuong, T.N., Gallegos, D. and Ramsey, R. (2015) Household Food Insecurity, Diet, and Weight Status in a Disadvantaged District of Ho Chi Minh City, Vietnam: A Cross-Sectional Study. BMC Public Health, 15, 232.

https://doi.org/10.1186/s12889-015-1566-Z

[23] Jomaa, L., Naja, F., Cheaib, R. and Hwalla, N. (2017) Household Food Insecurity Is Associated with a Higher Burden of Obesity and Risk of Dietary Inadequacies among Mothers in Beirut, Lebanon. BMC Public Health, 17, 567.

https://doi.org/10.1186/s12889-017-4317-5

[24] Gregório, M.J., Rodrigues, A.M., Graça, P., et al. (2018) Food Insecurity Is Associated with Low Adherence to the Mediterranean Diet and Adverse Health Conditions in Portuguese Adults. Frontiers in Public Health, 6, 38. https://doi.org/10.3389/fpubh.2018.00038

[25] Brotman, D.J., Golden, S.H. and Wittstein, I.S. (2007) The Cardiovascular Toll of Stress. The Lancet, 370, 1089-1100. https://doi.org/10.1016/S0140-6736(07)61305-1

[26] Parker, E.D., Widome, R., Nettleton, J.A. and Pereira, M.A. (2010) Food Security and Metabolic Syndrome in U.S. Adults and Adolescents: Findings from the National Health and Nutrition Examination Survey, 1999-2006. Annals of Epidemiology, 20, 364-370. https://doi.org/10.1016/j.annepidem.2010.02.009

[27] Berkowit, S.A., Gao, X. and Tucker, K.L. (2014) Food-Insecure Ietary Patterns Are Associated with Poor Longitudinal Glycemic Control in Diabetes: Results from the Boston Puerto Rican Health Study. Diabetes Care, 37, 2587-2592. https://doi.org/10.2337/dc14-0753

[28] Mazidi, M. and Vatanparast, H. (2018) Serum Trans-Fatty Acids Level Are Positively Associated with Lower Food Security among American Adults. Nutrition and Diabetes, 8, Article No. 17. https://doi.org/10.1038/s41387-017-0008-7

[29] Tait, C.A., L'Abbé, M.R., Smith, P.M. and Rosella, L.C. (2018) The Association between Food Insecurity and Incident Type 2 Diabetes in Canada: A Population-Based Cohort Study. PLoS ONE, 13, e0195962. https://doi.org/10.1371/journal.pone.0195962

[30] Seligman, H.K., Bindman, A.B., Vittinghoff, E., Kanaya, A.M. and Kushel, M.B. (2007) Food Insecurity Is Associated with Diabetes Mellitus: Results from the National Health Examination and Nutrition Examination Survey (NHANES) 1999-2002. Society of General Internal Medicine, 22, 1018-2013.

https://doi.org/10.1007/s11606-007-0192-6

[31] Fitzgerald, N., Hromi-Fiedler, A., Segura-Pérez, S. and Pérez-Escamilla, R. (2011) Food Insecurity Is Related to Increased Risk of Type 2 Diabetes among Latinas. 
Ethnicity and Disease, 21, 328-334.

[32] Pérez-Escamilla, R., Villalpando, S., Shamah-Levy, T. and Humarán, I.M. (2013) Household Food Insecurity, Diabetes and Hypertension among Mexican Adults: Results from Ensanut 2012. Salud Pública de México, 56, S62-S70.

https://doi.org/10.21149/spm.v56s1.5167

[33] Bawadi, H.A., Ammari, F., Abu-Jamous, D., et al. (2012) Food Insecurity I Related to Glycemic Control Deterioration in Patients with Type 2 Diabetes. Clinical Nutrition, 31, 250-254. https://doi.org/10.1016/j.clnu.2011.09.014

[34] Shariff, Z.M., Sulaiman, N., Jalil, R.A., et al. (2014) Food Insecurity and Metabolic Syndrome among Women from Low Income Communities in Malaysia. Asia Pacific Journal of Clinical Nutrition, 23, 138-147.

[35] Lyles, C.R., Wolf, M.S., Schillinger, D., et al. (2013) Food Insecurity in Relation to Changes in Hemoglobin $A_{1 c}$, Self-Efficacy, and Fruit/Vegetable Intake during a Diabetes Educational Intervention. Diabetes Care, 36, 1448-1453.

https://doi.org/10.2337/dc12-1961 